\title{
Avaliação do Conhecimento de Acadêmicos de Odontologia sobre a Avulsão de Dentes Permanentes Anteriores
}

Thaís Lima Lemes; Mariane de Oliveira Bento Ferreira; Kêmilly Mirelle Batista César; Ester Aquino de Sousa Moreira1; Regina Mota de Carvalho².

${ }^{1}$ Acadêmicos de Odontologia do Centro Universitário de Anápolis - UniEVANGÉLICA; ${ }^{2}$ Professora Adjunta do Curso de Odontologia do Centro Universitário de Anápolis - UniEVANGÉLICA.

\begin{abstract}
Resumo
Introdução: Avulsão dentária é o completo deslocamento do dente de seu alvéolo. É uma lesão traumática comum que acontece tanto na dentição decídua quanto na permanente sendo os dentes anteriores os mais acometidos devido a atividades recreativas. Objetivo/Metodologia: O objetivo do trabalho foi avaliar, através de um questionário, o conhecimento e as atitudes de acadêmicos do sétimo e oitavo período do Curso de Odontologia do Centro Universitário de Anápolis - UniEVANGÉLICA, frente a avulsão dentária, uma vez que dentes avulsionados apresentam prognóstico duvidoso. Resultados: O tempo fora da cavidade bucal e o meio de armazenamento são fatores determinantes, por esse motivo a adoção de medidas adequadas no momento do acidente é fundamental para o sucesso do reimplante. As respostas foram avaliadas através de estatística descritiva e inferencial. Conclusão: Concluiu-se que os acadêmicos demonstraram bom conhecimento atitudinal sobre a avulsão dentária, embora divergências tenham sido observadas quanto a forma de armazenamento do dente avulsionado.
\end{abstract}

Palavras-chave: Traumatismos dentários; Avulsão dentária; Padrões de prática odontológica.

\section{Introdução}

Avulsão dental é a completa retirada do dente de seu alvéolo de origem, podendo causar sérios danos histológicos à polpa, ao ligamento periodontal, cemento, e osso alveolar. Esse problema tem ganhado destaque na saúde pública alcançando altos índices de prevalência. Essas injurias ocorrem comumente em crianças e adolescentes onde nessa fase elas estão mais envolvidas em atividades esportivas, o que aumenta o risco de injurias dentais que podem resultar em danos funcionais e estéticos. Os procedimentos iniciais estão diretamente ligados ao sucesso nestes $\operatorname{casos}^{1,2}$.

Avulsão dentária na dentição permanente, ocorre com maior frequência em pacientes na faixa etária compreendida entre 7 e 11 anos de idade. Representa aproximadamente $15 \%$ das lesões traumáticas nessa fase ${ }^{3}$. Traumas dentários são considerados relativamente comuns tanto na dentição decídua como na permanente, sendo os incisivos superiores os dentes mais afetados ${ }^{4}$. O sexo masculino é considerado o mais afetado, principalmente durante período de férias na realização de atividades recreativas ${ }^{1}$. É considerada uma situação de urgência que exige uma conduta clínica imediata e correta do cirurgião-dentista, pois o tempo é fator determinante para aumentar a probabilidade de sucesso do tratamento ${ }^{5}$.

Isto, demonstra que o conhecimento e atitudes corretas frente a esta emergência é de extrema importância para um prognóstico favorável àquele paciente, onde grande parte destes dentes traumatizados são perdidos ou apresentam um prognóstico sombrio devido à falta de informação quanto às medidas de pronto atendimento adequadas no momento do acidente ${ }^{6}$. A literatura relata que, não somente os educadores, mas também os Cirurgiões Dentistas, apresentam deficiências em como agir nos casos de trauma dentário, permanecendo a dúvida quanto a tomada de decisão quanto ao armazenamento, transporte e estabilização do dente avulsionado 5 .

Portanto, o objetivo deste trabalho foi analisar o nível do conhecimento e atitudes dos acadêmi$\cos$ do $7^{\circ}$ e $8^{\circ}$ período do curso de odontologia do Centro Universitário de Anápolis - UniEVANGÉLICA, acerca da avulsão dentária de dentes permanentes anteriores no aspecto clínico e radiográfico, evidenciando se os futuros cirurgiões dentistas estarão aptos nas ações imediatas e na prevenção do trauma.

\section{Material e Métodos}

Trata-se de um estudo observacional quantitativo que teve como público alvo acadêmicos do sétimo e oitavo período do curso de Odontologia do Centro Universitário de Anápolis - UniEVANGÉLICA matriculados nas disciplinas de odontologia pediátri$\mathrm{ca}$, cirurgia e endodontia, tendo todos os participantes recebido e assinado o Termo de Consentimento Livre e Esclarecido (TCLE), com a ressalva de que nenhum deles poderia ter acesso a nenhum material informativo.

As informações foram coletadas a partir do questionário de Marzola; Rosa-Marques e Valarelli ${ }^{7}$ (2008), autoaplicável e sua estrutura foi composta por duas situações fictícias de dez perguntas de múltipla escolha. As perguntas de um a quatro, correspondiam à primeira situação, quando, por telefone, o profissional deveria orientar ao paciente ou responsável sobre a conduta a ser realizada até que o mesmo chegasse ao consultório odontológico, significando os cuidados quanto ao manuseio, limpeza e armazenamento do dente. Para a segunda situação, as perguntas de cinco a dez deveriam ser aplicadas quando o paciente já 
estivesse no consultório odontológico e o profissional então optaria pela melhor conduta em relação a limpeza, tratamento endodôntico, contenção, acompanhamento radiográfico e previsibilidade de sequelas. Após a tabulação dos dados, foi feita uma estatística descritiva na forma de frequência simples e percentual. Para tanto utilizou o programa estatístico SPSS para WINDOWS versão 21.0. Para a formatação da tabela e a composição foi utilizada software Microsoft Excel, 2018.

\section{Resultados}

Os dados obtidos através dos questionários empregados nesta pesquisa de campo foram apurados e apresentados nas duas tabelas inseridas nos subtópicos a seguir. Dentre os 66 entrevistados, um total de 66 acadêmicos de Odontologia foram incluídos na amostra. Sendo que nenhum entrevistado foi excluído por preenchimento incompleto do questionário.

$\mathrm{Na}$ primeira situação os acadêmicos foram questionados sobre como orientariam ao paciente a segurar o dente, ainda pelo telefone, considerando que tenha sofrido queda acidental na rua, em casa ou na escola e tenha ocorrido avulsão de um dente incisivo permanente (Tabela 1). A segunda situação sugere que o paciente tenha chegado ao consultório para atendimento odontológico de urgência (Tabela 2). orientar ao Cirurgião-Dentista a examinar outras áreas na busca de sinais de lesões ${ }^{8}$. Somado a isso, o exame radiográfico é citado na literatura como essencial, tanto para auxiliar no diagnóstico, como no controle posterior do trauma, tendo como objetivo identificar a ocorrência de alguma anormalidade, tanto no dente acometido como no seu sucessor permanente9. Portanto, o acompanhamento desses dentes é imperioso por um período de 5 anos para determinar o resultado (sucesso ou insucesso) do reimplante ${ }^{10}$. $\mathrm{Pa}$ cientes acometidos por trauma devem ser acompanhados cuidadosamente em intervalos frequentes e regulares por algum tempo depois da reimplantação ${ }^{8}$. Dentre os fatores mais relevantes para determinação do prognóstico do reimplante dental, o tempo fora da cavidade bucal e o meio de armazenamento são os mais importantes ${ }^{8,11-14}$. É a partir da integração desses dois fatores que pode-se tentar determinar o melhor plano de tratamento para o paciente buscando o sucesso do procedimento, e, assim, preservar o elemento dental de forma duradoura na cavidade oral. Porém, para outros autores, o que deve ser avaliado e considerado relevante para o prognóstico seria o tratamento inicial do dente, tempo de exposição menor que trinta minutos fora da cavidade oral, teste pulpar positivo, teste pulpar negativo, forame apical menor que $1,3 \mathrm{~mm}$, forame apical maior que 1,3 $\mathrm{mm}$ e dente não encontrado/ sem

Tabela 1 - Distribuição percentual sobre a orientação ao paciente pelo telefone.

\begin{tabular}{lll}
\hline Variáveis & N & $\%$ \\
\hline \multicolumn{2}{l}{ Como você orientaria ao paciente a segurar o dente? } \\
\hline (a) Pela Raiz; & 66 & 100,00 \\
(b) Pela Coroa; & & \\
(c) Em qualquer posição & & \\
\hline O que faria com o dente? & 32 & 48,48 \\
\hline (a) Não limparia; & 33 & 50,00 \\
(b) Limparia com água ou algum líquido; & 1 & 1,52 \\
\hline (c) Limparia com pano ou papel & & \\
\hline Como levaria o dente?
\end{tabular}

(a) Embrulhado em algum material seco;

$\begin{array}{lll}\text { (b) Imerso em algum líquido; } & 66 & 100,00\end{array}$

(c) Acondicionamento em gelo

Caso colocasse em algum líquido, qual seria?

\begin{tabular}{lll}
\hline (a) Soro fisiológico; & 3 & 4,50 \\
(b) Saliva; & 17 & 25,80 \\
(c) Leite & 46 & 69,70 \\
\hline
\end{tabular}

\section{Discussão}

O exame clínico é considerado um dos mais importante no processo de diagnóstico de traumas, pelo fato de lesões concomitantes terem a chance de estar presentes. A história da doença também pode possível reimplante/ severa condição periodontal ${ }^{12,14}$. Quando o cirurgião-dentista recebe um chamado a respeito de um dente totalmente avulsionado, deve orientar o responsável para que enxágue o dente imediatamente com saliva do paciente, água filtra- 
Tabela 2 - Distribuição percentual sobre como proceder o atendimento de urgência.

\begin{tabular}{|c|c|c|}
\hline Variáveis & $\mathbf{N}$ & $\%$ \\
\hline (a) Não limparia; & 15 & $22,70 \%$ \\
\hline (b) Limparia e irrigaria com soro fisiológico; & 50 & $75,80 \%$ \\
\hline (c) Faria a curetagem e lavaria com soro sob forte jato & 1 & $1,50 \%$ \\
\hline \multicolumn{3}{|l|}{ O que faria com o dente avulsionado em menos de 2 horas do trauma? } \\
\hline (a) Recolocaria sem tratamento endodôntico prévio ao reimplante; & 56 & $84,80 \%$ \\
\hline (b) Não recolocaria o dente em seu alvéolo; & 5 & $7,60 \%$ \\
\hline (c) Trataria endodonticamente antes de reimplantar & 5 & $7,60 \%$ \\
\hline \multicolumn{3}{|l|}{ Caso fizesse o reimplante, antes você Irrigaria o dente com } \\
\hline (a) Soro fisiológico em forte jato; & 1 & $1,50 \%$ \\
\hline (b) Irrigaria o dente suavemente com soro fisiológico; & 65 & $98,50 \%$ \\
\hline \multicolumn{3}{|l|}{ (c) Rasparia a raiz para remover impurezas e o ligamento periodontal } \\
\hline \multicolumn{3}{|l|}{ Pergunta 8: No caso de reimplante } \\
\hline \multicolumn{3}{|l|}{ (a) Não faria contenção; } \\
\hline (b) Faria contenção com fio de aço rígido; & 24 & $36,40 \%$ \\
\hline (c) Faria contenção com fios maleáveis & 42 & $63,60 \%$ \\
\hline \multicolumn{3}{|l|}{ Quais as consequências mais comuns após o reimplante? } \\
\hline (a) Reabsorção radicular externa do tipo inflamatória e necrose pulpar; & 27 & $40,90 \%$ \\
\hline (b) Reabsorção radicular externa do tipo substituição e anquilose; & 8 & $12,10 \%$ \\
\hline (c) As alternativas a e b estão corretas & 31 & $47,00 \%$ \\
\hline \multicolumn{3}{|l|}{ O exame radiográfico deve ser feito } \\
\hline \multicolumn{3}{|l|}{ (a) Somente na primeira consulta; } \\
\hline (b) Mensalmente durante a ano; & 33 & $50,00 \%$ \\
\hline (c) Periodicamente por 5 anos & 33 & $50,00 \%$ \\
\hline
\end{tabular}

da ou solução salina e em seguida o dente deve ser então reimplantado. O paciente deve segura-lo pela coroa, tentando não tocar na raiz, e, então, após reposicionado, deve procurar imediatamente o cirurgião-dentista. Se o paciente não consegue recoloca-lo no alvéolo, deve guardar o mesmo num meio apropriado até que o procedimento seja realizado por um profissional|8,11-14. Na presente pesquisa houve concordância entre $100 \%$ dos entrevistados que afirmaram orientar o paciente a segurar o dente avulsionado pela coroa e $48 \%$ orientariam o paciente a não limpar o dente, discordando do trabalho de Peterson et al. ${ }^{8}$ (2005), que os resultados mostraram que a maioria dos participantes realizariam limpeza no dente antes do reimplante. O tempo crítico de reposição de dente no alvéolo foi estabelecido em torno de 15 a 30 minutos após a sua avulsão ${ }^{14}$. Contudo, em circunstâncias menos favoráveis, tal conduta deve ser entendida como uma tentativa de salvar o elemento dental, tendo em vista que, invariavelmente, algum tipo de reabsorção radicular lenta ou acelerada ocorrerá, mesmo que a mais perfeita e cuidadosa técnica seja utilizada ${ }^{15}$. Períodos que excedam duas horas são geralmente associados a resultados ruins ${ }^{8}$. Porém, na atual pesquisa, ao perguntarmos o que os entrevistados fariam com o dente avulsionado até duas horas do trauma, $84 \%$ responderam que recolocariam o dente mesmo sem tratamento endodôntico prévio. Quando se trata de dentes decíduos que sofreram avulsão o reimplante é contraindicado, pois a necrose pulpar é um evento frequente. Além disso, há risco de se lesar o germe dentário permanente através do reimplante, pois o coágulo pode ser forçado na área do folículo ${ }^{10,16}$.

Existem muitas soluções que foram propostas e/ou testadas como meio de armazenamento para dentes avulsionados, a exemplo do leite, saliva ou água de $\operatorname{coco}^{17}$. A utilização de um meio inadequado, aumenta potencialmente o risco de necrose celular, que irá então conduzir a anquilose e a reabsorção por substituição radicular. O meio ideal de armazenamento deve estar prontamente disponível ou facilmente acessível ao local do acidente. Isto é essencial para rapidamente repovoar a superfície radicular com células do ligamento periodontal e prevenir a fixação dos osteoclastos no cemento ${ }^{15,17}$. A saliva contém substâncias potencialmente prejudiciais, tais como enzimas, bactérias e seus subprodutos. Apesar da saliva ser um meio prontamente disponível, dentes avulsionados não devem ser armazenados por mais de 30 minutos nela em termos de preservação do ligamento periodontal em dentes controlados radiograficamente. Tanto dentes emergidos na saliva como mantidos a seco, independente da temperatura e tempo, foram danosos a células do ligamento periodontal e devem ser evitados ${ }^{17}$. As propriedades biológicas do leite bovino pasteurizado, osmolaridade similar à do fluido extra-celular, substâncias nutricionais somadas a facilidade de aquisição, o fazem um bom meio para transporte de dentes avulsionados. O leite, por ser um meio isotônico, com pH ligeiramente alcalino e relativamente sem bactérias, é considerado um excelente 
meio de estocagem, pois é capaz de manter a viabilidade de células do ligamento periodontal $\left.\right|^{8,14,18}$. A solução salina balanceada de Hank, o Viaspan e a solução de Custodiol, preparados comercialmente são de acesso mais difícil, mas sua efetividade sobre as células periodontais é superior a do leite, mas o seu uso em locais onde avulsões dentárias podem ocorrer é impraticável. Os resultados do estudo de Özan et al ${ }^{19}$ (2007), indicaram que a água da torneira, a saliva, e o soro fisiológico eram todos ineficazes para a manutenção da viabilidade das células do ligamento periodontal|8,14,18. Portanto, $100 \%$ dos entrevistados no presente trabalho responderam corretamente que o paciente deveria levar o dente ao consultório imerso em "algum líquido". Já em relação a contenção, a estabilização de um dente avulsionado pode ser conseguida utilizando-se de uma variedade de materiais, como fios de aço, barras, fio de naylon, splints. O período de estabilização semi-rígida deve ser tão pequeno quanto o tempo necessário para o dente se tornar readerido normalmente de sete a dez dias. Neste intervalo as fibras gengivais já estarão reparadas $8,10,15,16$.

Nos casos em que há fraturas alveolares concomitantes ou que o dente avulsionado tenha sido mantido fora do alvéolo por muito tempo e em meio seco (prognóstico muito ruim), pode-se realizar uma contenção rígida após o reimplante. Esta deve permanecer por períodos mais prolongados, de 40 a 60 dias. Já que não existe mais ligamento periodontal, a anquilose será a única modalidade de cicatrização possível ${ }^{16}$. Estes estudos direcionam a resposta da questão 8 do presente trabalho, para contenção com fios maleáveis, já que nenhuma fratura óssea foi citada na situação fictícia proposta. Ainda assim, uma parcela considerável de $36 \%$ dos entrevistados que participaram de nosso trabalho, afirmaram que fariam contenção com fio de aço rígido e $63 \%$ fios maleáveis.

As reabsorções radiculares por substituição e/ ou inflamatória constituem as principais causas biológicas de perdas dentárias após o reimplante de dentes avulsionados ${ }^{7}$. Ambas as reabsorções radiculares podem ocorrer, separadamente ou ao mesmo tempo. Assim, 46\% dos participantes da pesquisa responderam corretamente a questão 9 que aborda o tema. Do ponto de vista do conhecimento radiográfico, devido a frequência com que ocorrem reabsorções radiculares e anquilose após avulsões dentárias, é muito importante a proservação como forma imprescindível de controle e manutenção do sucesso clínico ${ }^{18}$. Por tudo isso que foi exposto, pode-se considerar que o resultado da pesquisa no que se refere ao acompanhamento radiográfico de dentes reimplantados foi razoável, pois $50 \%$ dos entrevistados respondeu que realizaria exames radiográficos periodicamente por até 5 anos.

\section{Conclusão}

Em geral os acadêmicos demonstraram conhecimento atitudinal satisfatório no instruir, lidar e tratar o dente avulsionado. Todavia, foi percebido in- segurança nas respostas quanto a orientação dos meios adequados de armazenamento do transporte, até o atendimento clínico. Sugere-se portanto, reforço e/ ou capacitação dos acadêmicos e futuros profissionais nesse conteúdo, para uma padronização e maior chance de sucesso no atendimento prestado ao paciente.

\section{Referências}

1. Siqueira A, Gonçalves P. Avulsão dentária traumática acidental: cuidados odontológicos para o reimplante. Rev Faculdade Odontol Lins. 2012; 22(1): 47-55.

2. Ornellas P, Domingos H, Gomes C, Antunes L, Antunes L. Conhecimento e Atitudes com Relação ao Atendimento Emergencial das Injúrias Dentárias Traumáticas. J Health Sci. 2016; 18(2): 91-85.

3. Guedes $P$, Antonio $C$. Reabilitação bucal em odontopediatria: atendimento integral. 1.ed. Santos, São Paulo: Santos ISBN; 1999.

4. Moraes F. Avulsão dentária: Características gerais, sequelas e protocolos terapêuticos [Monografia]. Piracicaba: Universidade Estadual de Campinas, 2014.

5. Antunes D, Gonçalves $M$, Antunes D, Paula M, Leite F, Chaves M. O conhecimento de cirurgiões-dentistas sobre condutas clínicas nas avulsões e reimplantes dentários: estudo piloto. HU Rev. 2012; 38(1): 135-141.

6. Alves L, Freitas V, Rosendo R, Gominho L, Sarmento T. Avaliação do conhecimento de professores do ensino fundamental da rede particular sobre atendimento imediato de vítima de traumatismo dental. Rev. da Faculdade de Odontologia, 2015 set./ dez.; 20(3): 307-302.

7. Marzola C, Rosa-Marques R, Valarelli TP. Avulsão dental: o cirurgião-dentista sabe o que fazer? [Monografia]. Baurú: Colégio Brasileiro de Cirurgia e Traumatologia Buco- maxilo- facial, Hospital de Base da Associação Hospitalar; 2008.

8. Peterson LJ, Ellis E, Hupp JR, Tucker MR. Cirurgia Oral e Maxilofacial Contemporânea. 4 ed. Rio de Janeiro: Elsevier; 2005.

9. Corrêa MSNP. Odontopediatria na primeira infância. 2.ed. São Paulo, Brasil: Santos; 2005.

10. Maia SMAS, Travassos RMC, Mariz EB, Macêdo SM, Alencar TA. Conduta clínica do cirurgião-dentista ante a avulsão dental: Revisão de literatura. Rev Sul- Bras de Odont. 2006; 3; 42-47.

11. Rebouças $P$, Neto J, Sousa D. Fatores que influenciam no sucesso do reimplante dental. Pub UEPG: Ciências Biológicas e da Saúde. 2013 Jan/jun; 31-37.

12. Kostka E, Meissner S, Finke C, Mandirola M, Preissner S. Multidisciplinary Treatment Options of Tooth Avulsion Considering Different Therapy Concepts. Open Dent. Journal. 2014; 8; 180183.

13. Blakytny C, Surbuts C, Thomas A, Hunter ML. Avulsed permanent incisors: knowledge and attitudes of primary school teachers with regard to emergency management. Int J Paediatr 
Dent. 2001; 11:327-2.

14. Guedes P, Antonio C. Odontopediatria: atendimento integral. 7.ed. Santos, São Paulo: Santos ISBN; 2003.

15. Santos, MESM. O conhecimento de pais ou responsáveis sobre avulsão de dentes permanentes [dissertação de mestrado em Cirurgia e Traumatologia Bucomaxilofacial]. Porto Alegre: Pontifícia Universidade Católica do Rio Grande do Sul; 2006.

16. Andreasen JO, Andreasen FM. Traumatismo dentário: soluções clínicas. 2 ed. São Paulo: Panamericana, 1991.

17. Flores FW, Flores JA, Diesel PG, Bianchini AG, Bevilacqua WB. Meios de armazenamento para dentes avulsionado: revisão de literatura. Saúde Santa Maria, Suplemento - Artigos de revisão. 2016 Jul; 73-80.

18. Rodrigues RCP, Weber DR, Xavier CB. Avaliação clínica e radiográfica de pacientes submetidos a reimplantes dentários em um período de 10 anos. HU Rev 17., 2008; 38(3), 135-141.

19. Ozan F, Polat ZA, Er K, Ozan U, Değer O. Effect of propolis on survival of periodontal ligament cells: new storage media for avulsed teeth. J Endod. 2007;33(5):570-3.

\section{Autor Correspondente:}

Regina Mota de Carvalho*

Centro Universitário de Anápolis - UniEVANGÉLICA;

Curso de Odontologia. Avenida Universitária Km. 3, 5 -

Cidade Universitária, Anápolis - GO, 75083-515.

Telefone: +55 (62) 9 9906-1855

E-mail: regina.motacaravalho0@gmail.com

Recebido em : 08/11/2018

Aprovado em: 06/12/2018

Os autores declaram que não há conflitos de interesse.

\title{
Knowledge of Dental Students on Avulsion of Anterior Permanent Teeth
}

\begin{abstract}
Introduction: Tooth avulsion is the complete displacement of the tooth from its alveolus. It is a common traumatic injury that occurs both in the deciduous and in the permanent dentition, with the anterior teeth being the most affected due to recreational activities. Objective/Methods: The objective of the study was to evaluate, through a questionnaire, the knowledge and attitudes of seventh and eighth grade students of the University of Anápolis UniEVANGÉLICA Dental Course, regarding dental avulsion, since avulsed teeth present a dubious prognosis. Results: The time outside the oral cavity and the storage medium are determining factors, so the adoption of adequate measures at the time of the accident is fundamental for the success of the reimplantation. The answers were evaluated through descriptive and inferential statistics. Conclusion: It was concluded that the dental students demonstrated good attitudinal knowledge about dental avulsion, although divergences were observed regarding the storage form of the avulsed tooth.
\end{abstract}

Keywords: Tooth Injuries; Tooth avulsion; Practice Patterns; Dentists. 